\title{
UNIWERSYTET DZISIAJ
}

Ponieważ jestem historykiem z zawodu, to zastanawiając się nad współczesnym znaczeniem pojęcia uniwersytet, sięgam wstecz. Próbuję objąć tą refleksją drogę, jaką sam uniwersytet i jego rozumienie przebyły od swoich początków. Przypomnijmy zatem najpierw samo pojęcie uniwersytetu. Odwołuje się ono do wspólnoty, wspólnoty profesorów i studentów. O to chodzi w tym pojęciu przede wszystkim. To jest ta universitas nas obejmująca w poszczególnych uczelniach, ale jednocześnie słowo „uniwersytet” odwołuje się do innego pojęcia i jest z nim nierozerwalnie związane: to jest pojęcie u n i w e r s u m. To całość uporządkowana, którą nie po łacinie, ale po grecku oddaje dobrze wcześniejsze słowo „kosmos”, uwypuklające pewien ład, wspólnotę, którą możemy zobaczyć jako jedność. To jest właśnie owo u n i w e r s u m, które rozpoznajemy na uniwersytecie.

Kiedy zastanawiam się nad słowem „uniwersytet”, próbuję także zuchwale wykroczyć poza krąg znaczeń, które były już przecież przedmiotem refleksji od początku istnienia tej instytucji. Używając swobodnej gry skojarzeń słownych, można zwrócić uwagę na niezwykle bliskie pokrewieństwo słowa universitas ze słowem, które bardzo łatwo stworzyć usuwając tylko jedną literę: univeritas - jedna prawda, ,jednoprawda”.

Czy uniwersytet poszukuje jednej prawdy? Czy opiera się na jednej prawdzie? Wielu z nas uważa, że tak. Wielu z nas chciałoby do tego dążyć. Niezależnie jednak od tego, czy pozostawimy to skojarzenie - univeritas i universitas - tylko jako żart słowny, czy też potraktujemy je poważnie, pozostaje ta wcześniej wymieniona przez mnie poważna i na pewno historycznie potwierdzona wspólnota dwóch pojęć uniwersytetu, jako społeczności, porozumienia tych, którzy go tworzą: zarówno profesorów jak i studentów. Budują owo pojęcie we wzajemnej rozmowie, w relacjach mistrz-uczeń. To jest zwornik wspólnoty akademickiej. Jednocześnie uniwersytet to wspólnota badania świata, w którym chcemy rozpoznać i odkryć u n i w e r s u m, pewien porządek, jeden, jednoczący nas, ludzi, porządek. Otóż posuwając się w tej refleksji od początków, od genezy pojęcia uniwersytetu, do naszych czasów, by zobaczyć drogę, którą pokonuje instytucja uniwersytetu w ostatnim czasie, pozwolę sobie zatrzymać się na ważnym w kontekście tych rozważań momencie, mianowicie na roku 1978, dacie wyboru Karola Wojtyły na Stolicę 
Piotrową. Tak się złożyło, że dla wszystkich, którzy poczuwają się do przynależności do tak czy inaczej rozumianej generacji Jana Pawła II, rok ten stanowi zasadniczy początek, punkt wyjścia - rok otwarcia. Takim był też dla mnie, wtedy zaczynałem swoje studia na Uniwersytecie Jagiellońskim i wtedy jako młody człowiek, zastanawiający się nad tym nowym dla mnie światem, nad ową nową wspólnotą, w którą mam wejść, $\mathrm{z}$ radością i fascynacją zająłem się lekturą czasopisma, które wtedy było bardzo ważne, na pewno nie tylko dla mnie, a wydało właśnie specjalny numer. Mam na myśli miesięcznik „Znak” i jego monograficzny numer z czerwca 1978 roku, poświęcony uniwersytetowi. Pozwolę sobie wrócić raz jeszcze do tego numeru, który wciąż mam, z pietyzmem i sentymentem przechowuję i nie raz do niego w ciągu tych minionych czterdziestu jeden lat już sięgałem. Chcę odczytać fragmenty pomieszczonych tam w 1978 roku refleksji na temat uniwersytetu, na temat problemów, czy wręcz kryzysu, który już wówczas dostrzegano. Zebrano w owym numerze „Znaku” istotne myśli krytyczne i zarazem zamieszczono też pewne wskazówki, jak z kryzysu uniwersytetu w XX wiek wyjść. Pozwalam sobie przytoczyć te fragmenty, by zastanowić się, do jakiego stopnia udało się tamte dylematy rozwiązać. Czy i w jaki sposób możliwe było przezwyciężenie ówczesnego kryzysu? Jak my te rozterki poostrzegamy z perspektywy roku 2019? Pomieszczono tam także refleksje sięgające wstecz do Johna Henry'ego Newmana i jego Idei uniwersytetu, José Ortegi y Gasseta z jego Misja uniwersytetu oraz do myśli Karla Jaspersa zawartej w dziele Prawda badawcza, kształcenie i nauczanie. Dla naszych dalszych rozważań przytoczmy fragmenty dwu ostatnich z wymienionych tekstów.

Znajdujemy się dzisiaj - pisze Ortega y Gasset - chodź pewne domniemania i pozory wskazują na co innego, w epoce przerażającego braku kultury. Nigdy może przeciętny człowiek nie znajdował się tak głęboko poniżej swojego czasu, poniżej jego wymogów. Dlatego też nigdy nie było takiej obfitości istnień zafałszowanych, oszukańczych. Nikt prawie nie znajduje się na swoim miejscu, nie boryka się ze swoim autentycznym przeznaczeniem ${ }^{1}$.

Zwracano już wielokrotnie uwagę na potrzebę autentyczności jako warunku dobrej komunikacji z innymi. Brak autentyczności jest cechą naszych czasów tych, o których mówił Ortega y Gasset

Dzisiejszy człowiek żyje wykrętami z pomocą, których okłamuje samego siebie udając, że otaczający go świat jest bardzo prosty i poddający się arbitralnemu opisowi, chodź jego żywotna świadomość głośno każe mu stwierdzić, że prawdziwy świat odpowiadający całej pełni współczesności jest niezmiernie skomplikowany, złożony

\footnotetext{
${ }^{1}$ J. Ortega y Gasset, Misja uniwersytetu, tłum. H. Woźniakowski, „Znak”, nr 288, 6/1978, s. 726.
} 
i wymagający. On jednak boi się, przeciętny człowiek jest dzisiaj bardzo słaby, pomimo swoich gestów zabijaki. Boi się otworzyć na ów prawdziwy świat, który wiele by od niego wymagał i woli fałszować swoje życie, zamykając je w hermetycznym kokonie uproszczonej fikcyjnej rzeczywistości. Dlatego właśnie ma historyczną ważność przywrócenie uniwersytetowi jego podstawowego zadania jakim jest oświecenie człowieka. Wpajanie mu w pełni kultury danego czasu. Jasne i precyzyjne odsłanianie przed nim współczesnego świata w całym jego ogromie. Świata, w którym życie ludzkie musi się zakorzenić, aby zyskać swoją autentyczność².

I dalej, wskazówki czy rady jakich udziela w tym kontekście autor Buntu mas:

Przez uniwersytet stricto sensu będziemy rozumieć instytucję, w której przeciętnego studenta uczy się być człowiekiem kulturalnym i dobrym fachowcem. (...) Dyscypliny kulturowe i studia zawodu będą nauczane w formie pedagogicznie zracjonalizowanej, systematycznej i pełnej. Nie zaś w tej formie jaką najchętniej przybiera nauka pozostawiona samej sobie; problemów szczegółowych, wycinków nauki, prób badawczych ${ }^{3}$.

Ta sugestia, by uniwersytet wracał do swoich korzeni, do powszechności do refleksji nad u n i we r s u m i nad miejscem człowieka w nim zostaje jeszcze mocniej podkreślona w tekście, który także znalazł się w owym numerze „Znaku” w tłumaczeniu fragmentów obszerniejszego artykułu Karla Jaspersa poświęconego uniwersytetowi.

„Kształcenie uniwersyteckie to proces formacyjny zmierzający do rozumnej wolności. Dokonuje się on poprzez uczestnictwo w intelektualnym życiu uniwersytetu, ale jak to osiągnąć?”" - zastanawia się Jaspers i podkreśla, że najważniejszą cechą, potrzebną w życiu uniwersyteckim jest szacunek.

Szacunek jest niezbędny dla wychowania, bez niego pozostaje w najlepszym razie praktyczna sprawność. Szacunek stanowi sam rdzeń edukacji. Nasze człowieczeństwo domaga się od nas otwarcia na absolut, bez tego nic nie miałoby znaczenia. W obrębie świata ten absolut może się odzwierciedlać na trzech poziomach: wspólnotowym, a więc w grupie społecznej, do której nas przysposobiono; w państwie oraz w zinstytucjonalizowanej formie religii; na poziomie indywidualnym albo na obu równocześnie. W tej mierze w jakiej sama treść wychowania staje się problematyczna, sztywnieje ona i twardnieje, a respekt utrzymywany jest w sztuczny sposób, do czego też przyczynia się celowa skrytość rządzących. Respekt utrzymuje się także żądając śle-

2 J. Ortega y Gasset, Misja uniwersytetu, dz. cyt., s. 726.

3 J. Ortega y Gasset, Misja uniwersytetu, dz. cyt., s. 728.

${ }^{4}$ K. Jaspers, Praca badawcza, kształcenie, nauczanie, tłum. hm, „Znak”, nr 288, 6/1978, s. 742. 
pego posłuszeństwa dla sprawujących władzę i przez podsycanie ludzkiej skłonności do podporządkowania się. Samo zaś „spełnianie obowiązku” staje się namiastką pracy poświęconej temu, co w kształceniu zasadniczym. Zamiast dążyć do najcenniejszych osiągnięć na jakie ich stać, ludzie ubiegają się o zaspokojenie próżnych ambicji, o uznanie, o stanowisko. Zamiast formować całego człowieka, edukacja ogranicza się do wbijania w pamięć rzekomo użytecznych danych. Zamiast stawać się żywym wcieleniem pewnego ideału wychowawczego tacy ludzie interesują się tylko przyswajaniem sobie jedynie materiału faktycznego, który im prędko ucieknie z głowy, zapamiętywanego do czasu egzaminów mających im nadać status ludzi wykształconych ${ }^{5}$.

Surowe słowa myślicieli - Karla Jaspersa i Ortegi y Gasseta - o uniwersytecie, który nie spełnia swoich zadań, czytał w 1978 roku młody człowiek, który wtedy wstępował w progi najstarszej polskiej uczelni. Czytał - i miał nadzieję, że będzie inaczej. Dziś mogę owe sądy i nadzieje skonfrontować z aktualną oceną, z moim spojrzeniem, oczywiście partykularnym, subiektywnym, na współczesny stan uniwersytetów, ale także z refleksją, jaką prowadzi nad tym zagadnieniem godny kontynuator Jaspersa i Ortegi, Alasdair MacIntyre.

Trudno nie zgodzić się z opinią tego filozofa, najwybitniejszego może spośród żyjących, że dzisiejsze uniwersytety są przykładami niebywałego sukcesu. Na pierwszym poziomie to jest oczywiście sukces badawczy. Jeśli chodzi o odkrycia, o patenty, wdrożenia, ujmowane nie tylko w aspekcie praktycznym, ale także rozpatrywane $\mathrm{w}$ dziedzinie badań podstawowych, to widać, że osiągnięcia uniwersytetów w ostatnich czterdziestu latach są nie do podważenia. Uniwersytet jest także miejscem niewątpliwego sukcesu, który nazwać można twardo, surowo i krytycznie - sukcesu w produkowaniu zasobów ludzkich dla korporacji ${ }^{6}$. W tym samym kierunku zdają się prowadzić spostrzeżenia rektora Ziejki, zawarte w jego poruszającym artykule, a mówiące o pokusie przekształcania uniwersytetu w zakład usługowy, czy też korporację, którą łączą relacje ze studentami nie uniwersyteckie, ale stosunki typu usługodawca-klient. To wielka przestroga. Profesor Ziejka zwraca uwagę na zagrożenie niesione przez rozumienie relacji ze studentami w kategoriach kontraktu, którego finalnym owocem ma być kariera tegoż studenta. Wydaje mi się, że ta funkcja uniwersytetu jest spełniana coraz bardziej doskonale, ale też zarazem przez to uczelnia coraz bardziej oddala się od wspominanej wyżej z tęsknotą idei uniwersytetu. Rozumiem, że w każde uczelni musi być biuro karier, że troska o to, żeby nasi absolwenci odnaleźli się w życiu

${ }^{5}$ K. Jaspers, Praca badawcza, dz. cyt., s. 741.

${ }^{6}$ Por. A. MacIntyre, God, Philosophy, Universities. A Selective History of the Catholic Philosophical Tradition, Lanham 2011, 173; S. A. Stolz, MacIntyre, managerialism and universities, „Educational Philosophy and Theory”, Vol. 49, 2017/1, s. 38-46. 
praktycznym jest naturalna i dobra, ale jeżeli wszystko podporządkujemy temu właśnie zadaniu, by przygotować naszych studentów nie do odnalezienia swojego miejsca w u n i we rs u m, ale do odnalezienia swojego miejsca w korporacjach, takich jak uniwersytety lub innego typu wyższe uczelnie - to coś z misji uniwersytetu zostaje zaprzepaszczone...

I trzeci rodzaj ewidentnego osiągnięcia i widocznego postępu w życiu uniwersytetów, to jest ich zdumiewający sukces finansowy. Może to zabrzmieć jak paradoks, przecież brakuje nam ciągle pieniędzy, każdy rektor może to powiedzieć, ale jeśli porównamy skalę budżetów uniwersytetów sprzed czterdziestu lat i obecnie - to widzimy, że uniwersytety stają się dzisiaj gigantycznymi przedsiębiorstwami, obracają ogromnymi pieniędzmi i potrzebują ogromnych pieniędzy. Dostają może nie tyle środków, ile by chciały, ale zabiegają o nie przecież w duchu logiki korporacyjnej: mamy zadanie - realizujemy je - i dostajemy za to pieniądze.

Należy spytać, co tracimy przy takim kierunku ewolucji uniwersytetów. Nie wszyscy, oczywiście, zgodzą się z taką diagnozą, ale myślę, że warto takie właśnie prowokacyjne tezy stawiać, żeby pobudzić i zintensyfikować debatę. Znaczenie tego rodzaju dyskusji, rozumianej wszak jako zasada życia uniwersyteckiego - jest nieocenione Otóż wydaje mi się, że niezależnie od wspomnianych wyżej osiągnięć uniwersytetów w ciągu ostatnich czterdziestu lat, tracimy przede wszystkim poczucie jedności, poczucie owego u n i w e r s u m, poczucie, w którym szukalibyśmy nie sukcesu w jednej dziedzinie, ale łączności pomiędzy dziedzinami. Jedność pomiędzy nimi jest tym, co pozwala się nam jako ludziom odnajdywać w świecie jako kosmosie, nie pozwala nam ulec pokusie rozpaczy wobec chaosu, który tak łatwo możemy wokół siebie dostrzec - i na tym poprzestać.

Tracimy być może także samo pojęcie wykształcenia uniwersyteckiego, którego celem nie jest ani korzyść ekonomiczna, ani też przygotowanie karier studentów, tylko dążenie do pewnego wzajemnego porozumienia i do prawdy Uniwersytet jawił się zawsze dotychczas jako pewnego rodzaju szkoła sporu prowadzonego w granicach szacunku. Uniwersytet można by zdefiniować jako szkołę dochodzenia do prawdy przez spór w granicach szacunku. Trafne staje się określenie użyte już kilkadziesiąt lat temu przez Clarka Kerra, który analizując kryzys uniwersytetów w latach 70. XX wieku twierdził, że pojęcie uniwersytetu trzeba zastąpić określeniem „multiuniwersytety”7. Zanikło poczucie wspólnoty, w miejsce którego pojawiła się wielość partykularnych, rozbieżnych w swoich celach zadań, jakie mają realizować uczelnie - nazywane nadal uniwersytetami. Towarzyszy temu szersze zjawisko polegające na kryzysie pojęcia prawdy. Wielość prawd, przejście od wielości prawd do postprawdy, a nawet więcej: do prowadzonej przez fanatycznych ideologów postnowoczesności walki z „logocentryzmem”. Technik tej walki

\footnotetext{
7 C. Kerr, The Uses of the University, Cambridge, Mass. 1963.
} 
naucza się dziś z wielu najbardziej prestiżowych katedr uniwersyteckich na całym świecie. A chodzi w istocie o walkę ze słowem, z rozumem, z racjonalnością postrzeganymi wyłącznie jako narzędzia władzy, panowania („martwych białych samców”, takich jak Platon czy Mickiewicz). To jest dzisiaj trend nauczania obowiązujący na najbardziej postępowych i najważniejszych, najwyżej figurujących na rozmaitych listach rankingowych uniwersytetach. Walka z rozumem. Myślę, że to niebezpieczeństwo, jeśli ktokolwiek podziela tą diagnozę, warto rozpatrywać w perspektywie przejęcia uniwersytetu przez ducha biurokratycznego zarządzania, przez biurokratycznych menagerów, którzy zgodnie z logiką tego podejścia starają się powstrzymać racjonalną debatę, ponieważ racjonalna debata $\mathrm{z}$ wymiana argumentów nigdy nie wiadomo do czego doprowadzi. Bo nie wiemy, który argument zwycięży, jeśli wchodzimy w debatę. Natomiast jeśli chcemy planować rozwój naszego przedsiębiorstwa naszej korporacji musimy z góry założyć pewne rezultaty. Dlatego tworzy się udawane u n i w e r s u m, w którym udajemy pewną zgodę i powstrzymujemy faktycznie dyskusję, ponieważ może ona być w swoich rezultatach nieprzewidywalna. Ta sytuacja charakteryzuje się (także zgodnie z duchem owej menadżerskiej kontroli, dążenia do administracyjnego opanowania chaosu naukowej, akademickiej, w końcu ludzkiej po prostu rzeczywistości) obsesyjną skłonnością do nadużywania metod statystycznych, do próby wymierzenia prawdy życia uniwersyteckiego, kosmosu, u n i w e r s u m, za pomocą zestawień statystycznych ${ }^{8}$.

Każdy logik powie, że żadna ilość danych statystycznych nie przekłada się na wnioskowanie kauzalne, nie da się przejść z ilości w jakość; to tylko w podyktowanym przez Stalina Krótkim kursie WKP(b) było możliwe. Tymczasem tabelki statystyczne mają nas przekonać, co mamy robić, a czego robić nie powinniśmy, ponieważ będzie to nieopłacalne, albo nawet szkodliwe z punktu widzenia zarządzanego na sposób menadżerski uniwersytetu. Ten utylitaryzm zdominowany przez analizę kosztów, kosztów i zysków, zysków dających się zestawić w tabelce, uchwytnych w statystyce - służy właśnie temu, o czym wspomina w swym artykule także profesor Ziejka: to jest transformacja uniwersytetu w kontraktualną korporację. Usługodawca spotyka się z w niej klientem: studentem, albo z przedsiębiorstwem, albo z państwem, które to podmioty zamawiają u niego takie, czy inne wyniki. Otóż ta specyficzna ewolucja uniwersytetu łączy się jednocześnie ze zjawiskiem, o którym wspomniałem wcześniej. Zarządcy uniwersytetu, wielu uniwersytetów, nie mówię oczywiście o wszystkich, przekształcają się coraz bardziej, a w każdym razie chcą się pokazać światu, jako kompetentni menadżerowie, nie tylko menadżerowie zarządzający dobrze, sprawnie majątkiem, przedsiębiorstwem,

8 Znakomicie omawia ten trend S. A. Stolz, MacIntyre..., dz. cyt., s. 40-44, z której to analizy czerpię tutaj obficie. 
korporacją, ale kompetentni menadżerowie zmiany społecznej. Ta zmiana społeczna połączona z tą ewolucją, o której mówiłem wcześniej, ewolucją od pojęcia prawdy, do wielości prawd, do postprawdy, do walki z logocentryzmem, wykazuje jedną wspólną dynamikę: tj. dynamikę odchodzenia od prawdy.

To jest dynamika swoistej emancypacji, wyzwalania od prawdy. Analizował ten fenomen niezwykle głęboko Jan Paweł II w swoich dwóch wielkich encyklikach: Fides et ratio i Veritatis splendor. Papież pisał o tych zjawiskach, o tych przemianach, które przecież było widać już wiele, wiele lat temu.

Myślę, że owe niekorzystnie procesy da się ograniczyć, że warto próbować wykorzystać dziedzictwo uniwersytetu jako sposób na odzyskanie jego funkcji najważniejszej. Jaka to funkcja? Jeszcze raz przypomnę. Uczenie siebie nawzajem, profesorowie studentów, studenci profesorów, sporu w granicach szacunku. Dlaczego spór jest potrzebny? Ponieważ w dochodzeniu do prawdy nie możemy założyć z góry, że ją posiadamy. Są różne ścieżki prowadzące do prawdy i sytuacja, w której możemy się spierać na uniwersytecie - zawsze to podkreślam w granicach szacunku, jest jak najbardziej prawidłowa i twórcza. Jeśli natomiast przekraczamy te granice, spór łatwo staje się h e j t e m. Jeżeli jednak utrzymamy tę granicę szacunku, to podstawowym narzędziem uniwersytetu, w którym rozwijamy naszą zdolność poznawczą i zdolność poznawania samych siebie jest właśnie debata, spór - bo kiedy wchodzimy w spór, wówczas potrzebujemy pewnej empatii by zrozumieć stanowisko drugiego. Kiedy wchodzimy w spór - możemy zobaczyć, jak my jesteśmy postrzegani przez drugiego człowieka. I tu nawiążę do kwestii, pojawienia się w ostatnich kilkunastu, czy nawet kilkudziesięciu latach zupełnie nowych technologii. Technologii komunikacji masowej i tzw. mediów społecznościowych. Otóż wbrew nazwie, która do nich przylgnęła, media społecznościowe są to zasadniczo mediami anty-społecznościowymi, to są instrumenty, które zamykają nas w swoistych „bańkach informacyjnych”. Spotykamy się w nich z tymi, których poglądy podzielamy. Nie wchodzimy do innej „bańki”, do innej grupy na Facebooku - tylko mamy swoich przyjaciół na Facebooku, odczytujemy tylko to, co chcemy. A o tych, którzy myślą inaczej od nas, dowiadujemy się tylko od takich, którzy myślą tak samo jak my. Czyli de facto widzimy karykaturę poglądów innych. To pozamykanie w bańkach informacyjnych jest oczywiście zjawiskiem, które nie dotyczy tylko uniwersytetów, ale odnosi się do całego współczesnego świata zdominowanego właśnie przez tak sformatowane media społecznościowe. W ślad za nimi podążają także media elektroniczne, które stają się mediami integracyjnymi. Ich twórcy odwołują się do danej grupy, do danych poglądów, a o „tych drugich” gotowi są - dla integracji własnej grupy odbiorców - mówić tylko jak najgorzej. Zanikła agora we współczesnym świecie. Nie ma jej - tzn. nie ma miejsca wymiany poglądów, gdzie spotykamy się, każdy mówi we własnym imieniu, przedstawia swoją wizję i może w racjonalnej argumentacji zmienić swój pogląd, albo zmienić 
pogląd tego, z kim rozmawia. Takie miejsce zanikło. Kiedyś np. w Polsce było takie pismo „Rzeczpospolita”, które odgrywało tego rodzaju rolę. Dzisiaj na pewno już ani ten dziennik, ani żadne inne medium takiej roli nie jest w stanie udźwignąć. Każdy ma swoje pismo, czy swoje pisma, swoją grupę na Facebooku. Nie umiemy już rozmawiać między sobą.

I tu właśnie, w tym kryzysie publicznej rozmowy, racjonalnego dialogu, ujawnia się fundamentalna rola uniwersytetu. Uniwersytet powinien uczyć tego, że są ludzie, którzy z różnych perspektyw do prawdy dochodzą, przy założeniu, że jednak chcą dochodzić do jednej prawdy. Myślę, że niebezpieczeństwem, które przeszkadza w zrealizowaniu tej misji, niebezpieczeństwem coraz bardziej rozpowszechnionym, może jeszcze nie u nas, nie na naszych uczelniach, ale właśnie na tych najwyżej cenionych $w$ rankingach uniwersytetach zachodnich jest zjawisko wszechogarniającej, paraliżującej myśl „politycznej poprawności”. Definicja słownikowa tego pojęcia z Oxford Dictionary of New Words ujmuje znaczenie tego słowa następująco:

conformity to a body of liberal or radical opinion on social maters, characterize by the advocacy by approve views in the rejection of language behaviour consider discriminatory or offensive.

A więc „konformizm” jest pierwszym słowem, zgodność, odpowiedniość conformity to a body of liberal or radical opinion.

Musimy zatem być zgodni z pewną opinią, ideologiczną oczywiście; jej nie cechuje dążenie do prawdy, podaje tylko już odkrycie pewnej, uznanej za jedynie dopuszczalną, interpretacji, do której mamy się dostosować. Naszym zadaniem jest też wspieranie tych poglądów, które zostały uznane w środowisku dominującym ideologicznie za słuszne. Życie intelektualne ma się realizować nie za pomocą dialogu, nie w drodze argumentacji, tylko poprzez zakazy, zakazy głoszenia innych poglądów. Autor najobszerniejszej analizy pojęcia poprawności politycznej, Jeffrey Hughes, który na ten temat wydał nakładem Oxford University Press książkę, definiuje to pojęcie jeszcze inaczej i krócej:

Political correctness in sense of obligation or conformity in areas should be or are matters of choice?.

A więc w tych dziedzinach, w których powinniśmy się móc spierać, następuje zakaz sporu: nie można się spierać... Sądzę, że ta tendencja, która wcale nie

9 G. Hughes, Political Correctness: A History of Semantics and Culture, Oxford 2009, s. 13. 
jest nowa, nie pojawiła się dopiero w ciągu ostatnich dwudziestu, trzydziestu lat powinna także zwrócić naszą uwagę.

Dodać trzeba jeszcze jedno szersze zjawisko, z którym także uniwersytet współczesny powinien sobie radzić. Jest to fenomen, do opisu którego, oprócz terminu politycznej poprawności, można wprowadzić pojęcie kultury terapeutycznej. Gordon Allport, który zaproponował je siedemdziesiąt lat temu ${ }^{10}$, zakładał, że słowa bywają niebezpieczne, trzeba leczyć się z niebezpieczeństwa ich oddziaływania, trzeba prowadzić stale oprócz terapii jaką poleca się ludziom chorym, trzeba „kurować” także chore słowa, chore pojęcia, zakazywać pewnych słów, zmieniać ich znaczenie, by je leczyć. Ta kultura terapeutyczna, która traktuje dorosłych ludzi jak dzieci albo jak chorych, prowadzi właśnie, jak zaobserwował to wybitny socjolog angielski Frank Furedi, do stygmatyzacji sceptycyzmu ${ }^{11}$. A bez sceptycyzmu nie ma uniwersytetu. Jeżeli nie możemy sceptycznie odnosić się do pewnych „prawd”, a w istocie opinii, które są nam ogłaszane jako „prawdy objawione” - to nie ma mowy o uniwersytecie we właściwym tego słowa znaczeniu. Takie podejście prowadzi w konsekwencji do infantylizacji świata akademickiego, bo ktoś za nas mówi nam, że to jest niebezpieczne, nie powinniśmy tego ruszać. Jak dziecko, które może wsadzić palec do kontaktu, tak my, magistrzy (czyli mistrzowie) i profesorowie (czyli wyznawcy) uniwersyteckiego obowiązku dochodzenia do prawdy, jesteśmy przestrzegani przez kulturę terapeutyczną, by pewnych rzeczy nie robić, pewnych pojęć nie używać. Wyraża się w takim podejściu zaprzeczenie idei uniwersytetu, który staje się swoją doskonałą antytezą. Universitas, przypominam, to wspólnota profesorów i studentów. Natomiast w kulturze terapeutycznej jesteśmy podzieleni na pacjentów i terapeutów. Mamy leczyć naszych studentów. Jak nie - to sami zostaniemy poddani terapii... Nie ma większej przepaści między ludźmi niż ta właśnie, jaką tworzy przepaść między „terapeutą” a leczonym $\mathrm{z}$ „mentalnych zaburzeń”.

Otóż myślę, że w jakiejś mierze te zagadnienia, które zarysowałem celowo w sposób ostry, by obudzić dyskusję, by pobudzić refleksję - dają się odnieść także do zjawisk bardzo praktycznych, związanych z naszym życiem akademickim, tu i teraz w Polsce, w związku z wprowadzoną właśnie tzw. „Konstytucją dla nauki”. Tak się złożyło, że blisko rok temu w grudniu wystąpiłem z listem otwartym, który krytykował te zmiany. Podpisało się pod tym listem wielu zasłużonych uczonych o wielkim prestiżu, takich jak Andrzej Walicki, Jan Hertrich-Woleński, jak prezesi najważniejszych stowarzyszeń historycznych: Polskiego Towarzystwa Historycznego czy Stowarzyszenia Historyków Sztuki. Bardzo wielu wybitnych

${ }^{10}$ G. Allport, The Nature of Prejudice, Reading 1954.

${ }_{11}$ F. Furedi. On Tolerance: A Defence of Moral Independence, London and New York 2011, s. 142. 
humanistów i przedstawicieli nauk społecznych podpisało ten sprzeciw, wyrażając zaniepokojenie wobec pewnego aspektu zmian. Nie mam na myśli całej „Konstytucji dla nauki", ale o ten jej aspekt, który ilustruje omawiane dzisiaj przeze mnie zjawisko. Wszystko, w myśl założeń ustawowych „Konstytucji” ma być zmierzone wg. tabelek statystycznych. Statystyka i mierzalność mają nam uregulować całość życia akademickiego. Ministerialni menedżerowie nauki projektują zadania, które powinniśmy zrealizować. Wszystko będzie zmierzone i zważone, ale wszystkiego, a raczej właśnie tego, co najważniejsze, co najbardziej wartościowe w humanistyce, w naukach społecznych - nie da się zmierzyć, zwłaszcza miarami przyjętymi odgórnie, centralnie, w Ministerstwie.

Błędne koło własnych usiłowań dostrzegli nawet niektórzy „scjentometryści”. By nie wchodzić w szczegóły, odwołam się teraz do tekstu ogłoszonego przez jednego ze znawców tej bardzo szybko rosnącej paradyscypliny i pseudonauki, Miloša Jovanovicia, zaprezentowanego podczas 15 Międzynarodowej Konferencji Towarzystwa Scjentometrii i Infometrii. Ten tekst zatytułowany The vicious circle of evaluation transparency został wydany w $2015 \mathrm{roku}^{12}$. Wskazuje on, że rozpaczliwe wysiłki znalezienia wspólnego mianownika dla wszystkich rodzajów nauk i twórczych procesów, które powinny zaczynać się na uniwersytetach, muszą znaleźć sposób na wykazanie ich opłacalności. Koszt-zysk; ten prosty rachunek obowiązuje w każdej korporacji. W przypadku humanistyki i nauk społecznych tę opłacalność mają mierzyć punkty przyznawane wydawnictwom i czasopismom $\mathrm{z}$ list światowych, lansujących najbardziej modne tendencje ideologiczne. Mamy tam publikować najlepiej po angielsku, bo wtedy będzie rosło uznanie dla naszej nauki. Nasze uniwersytety będą pięły się w górę rankingów szanghajskich i innych. Jak to może wyglądać w praktyce, w praktyce nauk społecznych i humanistycznych, przypomniał niedawno eksperyment wykonany przez trójkę badaczy amerykańskich: anglistkę, matematyka i filozofa. Napisali oni wspólnie dwadzieścia artykułów i rozesłali do prestiżowych wysoko punktowanych czasopism z takich dziedzin jak gender studies, sexuality studies, race studies oraz critical theory łącznie niekiedy obejmowanych pojęciem grievance studies. Wszystkie teksty były świadomie stworzonym czystym bełkotem, wśród nich znalazły się takie perły jak $\mathrm{np}$. Rape culture and queer performativity at urban park dogs - proszę wybaczyć nie przetłumaczę tego tytułu. Albo np. przetłumaczono fragmenty Mein Kampf Adolfa Hitlera, gdzie tylko słowo „Żyd” zastąpiono słowem „biały mężczyzna”, żeby tekst został uznany nie tylko za akceptowalny, ale naukowy - przez współcze-

12 M. Jovanović, The Vicious Circle of Evaluation Transparency - An Ignition Paper, $15^{\text {th }}$ International Conference On Scientometrics \& Informetrics Issi, Istanbul 2015, https://www. researchgate.net/publication/279530982_The_Vicious_Circle_of_Evaluation_Transparency_-_ An_Ignition_Paper (dostęp: 9.9.2019). 
snych redaktorów uniwersyteckiego pisma... Siedem z dwudziestu tych prób „humanistyki krytycznej” zostało po wewnętrznych recenzjach peer review przyjętych do druku, sześć oczekiwało nadal na recenzje, a tylko sześć zostało odrzuconych. Jeden z tych artykułów otrzymał nawet wysoką nagrodę. Poprawioną Mein Kampf chętnie przyjęto w bardzo prestiżowym czasopiśmie feministycznej filozofii. Tekst o kulturze gwałtu na podstawie zachowań psów w parkach opublikował miesięcznik „Gender Place and Culture. Journal of Feminist Geography”. Oba te czasopisma są oczywiście bardzo wysoko punktowane na najbardziej prestiżowej „liście filadelfijskiej” - i w dalszym ciągu na niej pozostają ${ }^{13}$. Natomiast autorzy tej intelektualnej prowokacji stracili już swoje akademickie stanowiska pracy...Może to być także przyszłość polskich nauk społecznych i humanistyki - jeśli będzie mierzona bezwzględną walką o punkty z takich właśnie centralnie ustalanych, politycznie poprawnych list. Nie twierdzę bynajmniej, że na „liście filadelfijskiej” nie ma bardzo wartościowych naukowo czasopism także w dziedzinie humanistyki. Twierdzę natomiast, że traktowanie jako jedynie słusznego kompasu rozwoju nauk społecznych i humanistyki wskazań tej listy, czy też sporządzonej przez czysto finansową korporację Elsevier bazy literatury cytowanej SCOPUS, na pewno nie wyeliminuje naukowej makulatury. Przyczyni się natomiast z pewnością do stopniowej eliminacji tej części aktywności humanistów, o której pisał w swym tekście pan profesor Ziejka, cytując słowa Jana Pawła II. Bo to się nie będzie liczyło - to, czego nie da się zmieścić w systemie punktacji przewidzianej przez „Konstytucję dla nauki”. Społeczna rola humanistyki, popularyzacja wiedzy o historii, o literaturze, o kulturze myśli, to wszystko jest wyceniane na „0” - w kategorii „koszty i zyski”. Gdybym miał streścić jednym zdaniem moje obawy związane z tą sytuacją, przytoczyłbym słowa pewnego filozofa. Ów filozof, Immanuel Kant, napisał ponad dwa wieki temu:

z drewna tak krzywego, z jakiego zrobiony jest człowiek nie da się wystrugać nic $\operatorname{prostego~}^{14}$.

Menadżerowie chcą jednak stworzyć jak najprostsze narzędzie, by to drzewo obrabiać mierzyć oceniać, ostatecznie strugać. Takim narzędziem ma być nowa humanistyka, ta opłacalna i mierzalna, standardami opracowanymi w cieniu centralnego gabinetu. Według najnowszych wzorów scjentometrii i infometrii. Myślę, że wobec tego zagrożenia, warto na koniec przywołać słowa, które powin-

13 J. Schuessler, Hoaxers Slip Breastaurants and Dog-Park Sex Into Journals, „New York Times", 4.10.2018: https://www.nytimes.com/2018/10/04/arts/academic-journals-hoax.html (dostęp: 9.9.2019).

${ }_{14}$ I. Kant, Idea powszechnej historii w aspekcie kosmopolitycznym, przekład M. Żelazny, [w:] I. Kant, Rozprawy z filozofii historii, Kęty 2005, s. 36. 
ny nam przywrócić przytomność i powinny być wskazaniem jak ratować uniwersytety przed stoczeniem się po tej równi pochyłej. To są słowa z wprowadzenia do encykliki Fides et Ratio, słowa, które rzeczywiście chyba najzwięźlej oddają istotę zadania jakie stoją przed uniwersytetem:

Im bardziej człowiek poznaje rzeczywistość i świat tym lepiej zna siebie jako istotę jedyną w swoim rodzaju, a zarazem coraz bardziej naglące staje się dla niego pytanie o sens rzeczy i jego własne istnienie. Wezwanie "poznaj samego siebie” wyryte na architrawie świątyni w Delfach stanowi świadectwo fundamentalnej prawdy, którą powinien uznać za najwyższą zasadę każdy człowiek określający się pośród całego stworzenia, właśnie jako człowiek, czyli ten, który poznaje samego siebie ${ }^{15}$.

\section{Abstract \\ University today}

The author analyses contemporary university crisis in terms of its traditional/original universalist vocation as the forum where truth is sought and debated. Developing older arguments of José Ortega y Gasset, Karl Jaspers and Alasdair MacIntyre, the text presents new challenges to that vocation - in a sui generis managerial revolution which took over academic life, as well as in the form of contemporary „political correctness”, understood as the obstacle for free exchange of arguments. Finally the text analyses potential dangers for academic life stemming from the recent (2018-2019) reform of universities in Poland (so called "Constitution for Science").

Keywords: university, education, political correctness, corporative norms

${ }^{15}$ Cyt. za: Encykliki Ojca Świętego Jana Pawła II, Kraków 2005, s. 699. 